\title{
Feeding long-chain $n-3$ polyunsaturated fatty acids to obese leptin receptor-deficient JCR:LA-cp rats modifies immune function and lipid-raft fatty acid composition
}

\author{
Megan R. Ruth ${ }^{1,2}$, Spencer D. Proctor ${ }^{1}$ and Catherine J. Field ${ }^{1,2} *$ \\ ${ }^{1}$ Nutrition \& Metabolism Research Group, University of Alberta, Edmonton, AB, Canada T6G 2P5 \\ ${ }^{2}$ University of Alberta, 4-126a HRIF-east, Edmonton, AB, Canada T6G 2E1 \\ (Received 16 April 2008 - Revised 29 July 2008 - Accepted 20 August 2008 - First published online 15 December 2008)
}

Dietary EPA and DHA modulate immunity and thereby may improve the aberrant immune function in obese states. To determine the effects of feeding fish oil (FO) containing EPA and DHA on splenocyte phospholipid (PL) and lipid-raft fatty acid composition, phenotypes and cytokine production, 14-week-old obese, leptin receptor-deficient JCR:LA-cp rats $(c p / c p ; n 10)$ were randomised to one of three nutritionally adequate diets for 3 weeks: control (Ctl, $0 \% \mathrm{EPA}+$ DHA); low FO (LFO, $0.8 \%$ (w/w) EPA + DHA); high FO (HFO, 1.4\% (w/w) EPA + DHA). Lean JCR:LA$c p(+/-$ or $+/+)$ rats $(n 5)$ were fed the $C t$ diet. Obese Ctl rats had a higher proportion of $n-3$ PUFA in splenocyte PL than lean rats fed the same diet $(P<0 \cdot 05)$. The lower $n-6: n-3$ PUFA ratio of splenocyte PL was consistent with the lower mitogen-stimulated interferon (IFN)- $\gamma$ and IL$1 \beta$ production by cells from obese rats $(P<0 \cdot 05)$. Obese rats fed the FO diet had lower mitogen-stimulated Th1 (IFN- $\gamma)$ and Th2 (IL-4) cytokine responses, but IL-2 production (concanavalin A; ConA) did not differ $(P<0 \cdot 05)$. The HFO diet was more effective in lowering IL-1 $\beta$ and increasing IL-10 production (ConA, $P<0 \cdot 05$ ). This lower IL-1 $\beta$ production was accompanied by a lower proportion of major histocompatability complex class II-positive cells and a higher incorporation of DHA into lipid rafts. This is the first study to demonstrate impaired responses to mitogen stimulation and altered fatty acid incorporation into the membrane PL of JCR:LA- $c p$ rats. Feeding FO lowered the ex vivo inflammatory response, without altering IL-2 production from ConA-stimulated splenocytes which may occur independent of leptin signalling.

Obesity: Fish oil: Immunity: Lipid rafts: Cytokines

It is well established that higher levels of circulating biomarkers of inflammation are present in the obese state, strongly suggesting inappropriate immune activation or regulation (as reviewed by Warnberg \& $\operatorname{Marcos}^{(1)}$ ). In addition, obese individuals are more likely to develop other chronic inflammatory conditions, including certain forms of cancer ${ }^{(2,3)}, \mathrm{CVD}$ and type 2 diabetes, and specific markers of inflammation can predict the development of $\mathrm{CVD}^{(4,5)}$ and type 2 diabetes $^{(6)}$. Impairments in the acquired immune system have also been identified in the overweight population. Individuals with a higher BMI are reported to be at an increased risk of infection and infection-related mortality (as reviewed by Falagas \& $\operatorname{Kompoti}^{(7)}$ ), have poor antibody responses to vaccines ${ }^{(8-10)}$ and immune cells have a reduced capacity to proliferate when stimulated with T-cell mitogens ${ }^{(11,12)}$. Overall, these studies support that immune function is abnormal in obesity, although the literature on human subjects is sparse. It is generally concluded that dysregulation of inflammatory responses is the key link among the metabolic syndrome, CVD and type 2 diabetes.

The JCR:LA-cp rat is a genetic model of obesity that expresses a dysfunctional leptin receptor which prevents any known receptor (ObR)-mediated signal of leptin. Rats that are homozygous for the autosomal recessive $c p$ gene $(c p / c p)$ are obese and insulin resistant, have dyslipidaemia and develop atherosclerosis ${ }^{(13-15)}$. Consequently, this model has been used extensively to study the impact of metabolic syndrome on various parameters of CVD; however, this is the first study to examine immune function. Several researchers have demonstrated that overweight human subjects also have higher circulating levels of inflammatory mediators (as reviewed by Warnberg \& $\operatorname{Marcos}^{(1)}$ ). Although one group has noted impairments in the proliferative response to T-cell mitogens ${ }^{(11,12)}$, the contribution of T-cells to inflammation or the effect of inflammation on T-cell function in the obese state is unknown.

It is well established that dietary nutrients, particularly lipids, can influence T-cell function and the inflammatory response ${ }^{(16)}$. Of particular interest in the literature has been the $n$-3 PUFA, EPA and DHA, which have potent effects on immunity and inflammation that improve chronic inflammatory conditions (as reviewed by Calder ${ }^{(17)}$ ). However, the impact of feeding fish oil to obese rodents on immune parameters is limited to only three studies, including one that

Abbreviations: ConA, concanavalin A; Ctl, control; FO, fish oil; HFO, high FO; IFN, interferon; LFO, low FO; LPS, lipopolysaccharide; MHC, major histocompatability complex; PL, phospholipid; PWM, pokeweed mitogen.

* Corresponding author: Catherine J. Field, fax +1 780 492-2011, email catherine.field@ualberta.ca 
reported no effect of fish oil on serum TNF- $\alpha$ concentrations ${ }^{(18)}$. One research group, using macrosomic offspring of diabetic rat dams, reported that feeding EPA and DHA improved the proliferative response of splenocytes to concanavalin A (ConA) and lowered the Th1:Th2 of serum cytokines $^{(19,20)}$. These studies indicate that feeding fish oil to obese offspring lowers the Th1 inflammatory response and improves the T-cell proliferative response; however, there is little support for the EPA and DHA's role in more specific aspects of the innate immune system in obesity.

Although the immune-modifying potential of EPA and DHA has been examined in various chronic inflammatory states, there is very little evidence for their effects on immune health in overweight adults. Collectively, these studies indicate that supplementing mixtures of EPA and DHA $(1 \cdot 1-4.2 \mathrm{~g} / \mathrm{d})$ for a short duration (6-12 weeks) have only a limited effect on systemic markers of inflammation in obese men or women, but offer little insight into the direct impact of long-chain $n-3$ PUFA on immune cell function $^{(21-24)}$.

An emerging area of interest in immunology is the role that lipid rafts have on immune cell signalling and general function. Lipid rafts are membrane microdomains found within the plane of the plasma membrane. They are enriched in cholesterol and sphingolipid and are insoluble in non-ionic detergents at low temperatures ${ }^{(25)}$. Lipid rafts serve as platforms for the aggregation of specific membrane-bound components requiring coordinated assembly for signal transduction (as reviewed by Dykstra et al. ${ }^{(26)}$ ). Recently, it was concluded that lipid rafts may be partly responsible for the $n$-3 PUFA-mediated effects on immune cells (as reviewed by Shaikh \& Edidin ${ }^{(27)}$ ); however, these studies are limited to in vitro experiments or studies involving healthy mice.

The objectives of the present study were to determine whether immune function was altered in obese JCR:LA-cp rats fed a high $n-6$ PUFA diet and whether feeding a diet supplemented with long-chain $n$-3 PUFA would (1) improve the immune dysfunction present in the JCR:LA- $c p$ rat and (2) alter the fatty acid composition of lipid rafts in immune cells of obese rats. Furthermore, we chose to examine two levels of EPA and DHA: the lower level to reflect what could be easily achieved through supplements and dietary modifications and the higher level to represent therapeutic levels, which would require considerable manipulation of the food supply and greater supplementation.

\section{Methods}

All animal care and experimental protocols were conducted in accordance with the Canadian Council on Animal Care and approved by the Faculty of Agricultural, Life and Environmental Sciences Animal Ethics Committee at the University of Alberta. Male obese $(c p / c p)$ and lean $(+/+$ or $+/-)$ rats of the JCR:LA-cp strain were raised in our breeding colony at the University of Alberta. All animals were individually housed in a temperature- and humidity-controlled environment with a $12 / 12 \mathrm{~h}$ reversed light cycle.

The animals were weaned at 3 weeks of age and given free access to water and a standard laboratory rat non-purified diet (Lab diet 5001; PMI Nutrition International, Brentwood, MO, USA). At 12 weeks of age, $1 \%$ (w/w) cholesterol
(Sigma-Aldrich, Oakville, ON, Canada) was added to the rat non-purified diet of all rodents for 2 weeks to accelerate the atherosclerotic disease process in the JCR:LA- $c p$ rodents ${ }^{(28)}$. At 14 weeks, $c p / c p$ rats were randomly allocated to receive one of the following nutritionally complete diets $(n$ 10) for 3 weeks: control (0\% EPA + DHA, $1 \%$ (w/w) cholesterol); low fish oil (LFO, $0.8 \%(\mathrm{w} / \mathrm{w})$ or $1.7 \%$ of energy EPA + DHA, $1 \%(\mathrm{w} / \mathrm{w})$ cholesterol); high fish oil (HFO, $1.4 \%(\mathrm{w} / \mathrm{w})$ or $3.1 \%$ of energy EPA + DHA, $1 \%$ (w/w) cholesterol). Moreover, lean $(+/+$ or $+/-)$ rats $(n 5)$ were allocated to the control diet for 3 weeks. A 3-week feeding period was chosen based on a previous dietary intervention study in the JCR:LA- $c p$ rats ${ }^{(29)}$. The nutrient composition of the experimental diets is provided in Table 1 and the fatty acid composition of the fat included in these diets is provided in Table 2. Fresh batches of diet containing oil were prepared weekly and stored at $4{ }^{\circ} \mathrm{C}$ until fed; feed cups were replaced every $2-3 \mathrm{~d}$ to ensure that the lipid did not oxidise. The rats were weighed and feed consumption, adjusted for food spillage, was recorded twice weekly. After an overnight fast, the rats were killed by cardiac exsanguination under isoflurane anaesthesia. Blood was collected via cardiac puncture in BD Vacuntainer ${ }^{\circledR}$ (BD Biosciences, Mississauga, ON, Canada) and serum stored at $-80^{\circ} \mathrm{C}$ until later analysis. The spleen was removed under aseptic conditions.

\section{Isolation of splenocytes and primary culture conditions}

The spleens were weighed and placed in sterile $0.5 \%(\mathrm{w} / \mathrm{v})$ bovine serum albumin in Krebs-Ringer-HEPES buffer $(\mathrm{pH}$ $7 \cdot 4$ ) and isolated as we have previously described ${ }^{(30)}$. Isolated splenocytes were resuspended in complete culture media (RPMI-1640 supplemented with 5\% (v/v) heat-inactivated fetal calf serum, $1 \%(\mathrm{v} / \mathrm{v})$ antimycotic-antibiotic solution,

Table 1. Composition of the experimental diets $(\mathrm{g} / \mathrm{kg})$

\begin{tabular}{|c|c|c|c|}
\hline & \multicolumn{3}{|c|}{ Diet } \\
\hline & Ctl & LFO & $\mathrm{HFO}$ \\
\hline Casein (high protein)* & 267 & 267 & 267 \\
\hline Maize starch & 212 & 212 & 212 \\
\hline Dextrose* & 215 & 215 & 215 \\
\hline Non-nutritive cellulose* & 79 & 79 & 79 \\
\hline AOAC vitamin mix $^{*}$ & $9 \cdot 4$ & $9 \cdot 4$ & $9 \cdot 4$ \\
\hline Bernhart-Tomerelli Mineral Mix & 48 & 48 & 48 \\
\hline Choline bitartrate $^{*}$ & $2 \cdot 7$ & $2 \cdot 7$ & 2.7 \\
\hline Inositol ${ }^{*}$ & $6 \cdot 2$ & $6 \cdot 2$ & $6 \cdot 2$ \\
\hline L-Methionine* & 2.5 & 2.5 & 2.5 \\
\hline Cholesterolł & 10 & 10 & 10 \\
\hline \multicolumn{4}{|l|}{ Oil } \\
\hline Flaxseed oil§ & 3 & 3 & 3 \\
\hline Stearin & 91 & 91 & 94 \\
\hline Sunflower oil† & 54 & 40 & 24 \\
\hline Fish oil $^{\star \star}$ & 0 & 15 & 28 \\
\hline
\end{tabular}

Ctl, control; LFO, low fish oil; HFO, high fish oil.

*Harlan Teklad (Madison, WI, USA).

† Save-On-Foods (Edmonton, AB, Canada).

‡Sigma (Oakville, Canada).

$\S$ Holistic ${ }^{\circledR}$ Flaxseed Oil (London Drugs, Edmonton, AB, Canada).

II Completely hydrogenated soyabean oil (CanAmera, Edmonton, AB, Canada).

ๆ Safeway (Edmonton, AB, Canada).

${ }^{\star *}$ Fish oil contained $3 \mathrm{mg} / \mathrm{g}$ mixture of $\alpha$-tocopherols (Ocean Nutrition, Dartmouth, NS, Canada). 
Table 2. Fatty acid composition of the experimental diets $(\mathrm{g} / 100 \mathrm{~g}$ fatty acids)

\begin{tabular}{lccc}
\hline & & Diet & \\
\cline { 2 - 4 } & Ctl & LFO & HFO \\
\hline $14: 0$ & $0 \cdot 08$ & $0 \cdot 14$ & $0 \cdot 13$ \\
$16: 0$ & $8 \cdot 5$ & 11 & $7 \cdot 6$ \\
$18: 0$ & 54 & 54 & 56 \\
$18: 1 n-9$ & $9 \cdot 3$ & $8 \cdot 4$ & $5 \cdot 5$ \\
$18: 2 n-6$ & 23 & 17 & 17 \\
$18: 3 n-6$ & $0 \cdot 03$ & $0 \cdot 00$ & 0.01 \\
$18: 3 n-3$ & $1 \cdot 3$ & $1 \cdot 6$ & $1 \cdot 2$ \\
$20: 5 n-3$ & $0 \cdot 00$ & $3 \cdot 7$ & $6 \cdot 4$ \\
$22: 5 n-3$ & $0 \cdot 00$ & $0 \cdot 02$ & $0 \cdot 01$ \\
$24: 0$ & $0 \cdot 15$ & $0 \cdot 18$ & $3 \cdot 0$ \\
$22: 6 n-3$ & $0 \cdot 00$ & $1 \cdot 7$ & $6 \cdot 7$ \\
Total MUFA & 10 & $9 \cdot 1$ & 28 \\
Total PUFA & 25 & 24 & 65 \\
Total SFA & 65 & 66 & 0.4 \\
PUFA:SFA & $0 \cdot 4$ & $0 \cdot 4$ & 17 \\
Total $n-6$ PUFA & 24 & 18 & 11 \\
Total $n$-3 PUFA & $1 \cdot 3$ & $7 \cdot 0$ & 2 \\
$n-6: n-3$ PUFA & 19 & 3 & $9 \cdot 4$ \\
Total EPA + DHA & $0 \cdot 0$ & $5 \cdot 4$ & \\
\hline
\end{tabular}

Ctl, control; LFO, low fish oil; HFO, high fish oil; SFA, sum of SFA; MUFA, sum of MUFA; $n-6$ PUFA, sum of $n-6$ PUFA; $n-3$ PUFA, sum of $n-3$ PUFA.

HEPES (25 mmol/l) and 2-mercaptoethanol $(2.5 \mathrm{mmol} / \mathrm{l}))$ and counted on a haemocytometer (Fisher Scientific, Edmonton, $\mathrm{AB}$, Canada). The essential fatty acid composition (w/w) of the fetal calf serum was as follows: $4.4 \% 18: 2 n-6 ; 0.1 \%$ $18: 3 n-3 ; \quad 0.5 \% \quad 20: 2 n-6 ; \quad 3 \% \quad 20: 4 n-6 ; \quad 0 \cdot 1 \% \quad 20: 5 n-3$; $0.1 \% 22: 4 n-6 ; 0.3 \% 22: 5 n-3 ; 0.8 \% 22: 6 n-3$. Splenocytes $\left(1.25 \times 10^{6}\right.$ cells/l) were resuspended in the culture media, as previously described, and incubated in $4 \mathrm{ml}$ sterile polystyrene tubes in a humidified atmosphere at $37^{\circ} \mathrm{C}$ in the presence of $5 \%(\mathrm{v} / \mathrm{v}) \mathrm{CO}_{2}$. Splenocytes were cultured without mitogen (unstimulated cells) or with ConA $(2.5 \mathrm{mg} / \mathrm{l})$, bacterial lipopolysaccharide (LPS; $1 \mathrm{mg} / \mathrm{l}$ ) or pokeweed mitogen $(\mathrm{PWM} ; 55 \mathrm{mg} / \mathrm{L})$ as previously described ${ }^{(31)}$. After $48 \mathrm{~h}$ of culture, the supernatant was removed and stored at $-80^{\circ} \mathrm{C}$ until cytokine assays were performed. Preliminary studies confirmed that by $48 \mathrm{~h}$ the maximum production of cytokines was achieved for cells from both lean and obese rats (data not shown).

\section{Phenotype analysis}

Immune cell subsets in freshly isolated splenocytes were identified by a one-, two- or three-colour direct immunofluorescence assay, as previously described ${ }^{(32)}$. The following pre-labelled mAbs were used: CD3, OX6 and CD28 (FITClabelled); CD4, CD8, CD3, CD11b/c and OX12 (PE-labelled); CD25 and CD8 (biotin-labelled). All antibodies were purchased from BD Biosciences, PharMingen (Mississauga, ON, Canada) except CD4 and OX12, which were purchased from Serotec (Cedarlane Laboratories Ltd, Hornby, ON, Canada) and Streptavidin-Quantum $\operatorname{Red}^{\mathrm{TM}}$ was purchased from Sigma-Aldrich (Oakville, ON, Canada). StreptavidinQuantum $\operatorname{Red}^{\mathrm{TM}}$ (R-PE-Cy5 flurochrome) was added to wells containing biotin-labelled $\mathrm{Ab}$. After the final wash, plates were aspirated and $200 \mu \mathrm{l}$ of cell fix $(1 \%$ (w/v) paraformaldehyde) was added to each well. The proportion of cells that were positive for each marker was determined by flow cytometry (FACScan; BD Biosciences, Mississauga, ON, Canada) according to the relative fluorescence intensity using the CellQuest software (BD Biosciences, Mississauga, ON, Canada).

\section{Cytokine production and serum haptoglobin}

All of the following assays were performed according to the manufacturer's instructions. The cultured cell supernatants of unstimulated, ConA, bacterial lipopolysaccharide and PWM-stimulated splenocytes were used to determine IL-1 $\beta$ and TNF- $\alpha$ (detection limit: $31 \cdot 2-2000 \mathrm{pg} / \mathrm{ml})$, IL-2 (23.4$1500 \mathrm{pg} / \mathrm{ml})$, IL-4 (1.6-100 pg/ml), IL-6 (78-5000 pg/ml), IL-10 $(15 \cdot 6-1000 \mathrm{pg} / \mathrm{ml})$ and interferon (IFN)- $\gamma(31 \cdot 25-$ $2000 \mathrm{pg} / \mathrm{ml}$ ) levels with OptEIA anti-rat (ELISA) sets were purchased from BD Biosciences, PharMingen (Mississauga, ON, Canada). The values below the range of detection were assigned half of the value of the lowest standard value. The serum haptoglobin levels were determined by a colorimetric assay purchased from Tri-Delta Development Limited (Maynooth, Ireland), according to the manufacturer's instructions. All samples were measured in duplicate and the absorbance for cytokine assays was measured at 450 and $630 \mathrm{~nm}$ for haptoglobin on a microtitre plate reader (SPECTRAmax 190, Molecular Devices, Sunnyvale, CA, USA). If the coefficient of variance exceeded $10 \%$ for duplicate samples, the samples were rerun. The average of the duplicate data with a coefficient of variance of $\leq 10 \%$ was used for statistical analysis.

Lipid-raft isolation. Lipid rafts were isolated from unstimulated, freshly isolated splenocytes from obese rats only, as previously described by our group ${ }^{(33)}$. Briefly, $2 \times 10^{8}$ of freshly isolated splenocytes were lysed in $500 \mu \mathrm{l}$ of TNE (25 mM-Tris-Cl, pH 7.5, $150 \mathrm{mm-NaCl}, \quad 5$ mM-EDTA) containing $1 \%(\mathrm{v} / \mathrm{v})$ Triton X-100 (VWR) with fresh protease and phosphatase inhibitors (Sigma-Aldrich) for $30 \mathrm{~min}$ at $4^{\circ} \mathrm{C}$. Lysates were spun for $30 \mathrm{~min}$ at $4^{\circ} \mathrm{C}(1000 \mathrm{rpm})$ and the supernatant was transferred to cooled ultracentrifuge tubes (Beckham Coulter, Mississauga, ON, Canada). An $80 \%(w / v$, $800 \mathrm{~g} / \mathrm{l}$ in TNE) sucrose solution was added to the supernatant to make a $40 \%(\mathrm{w} / \mathrm{v})$ sucrose solution. The lysates were gently overlaid with $2 \mathrm{ml}$ of a $30 \%(\mathrm{w} / \mathrm{v}, 300 \mathrm{~g} / \mathrm{l}$ in TNE) sucrose solution, followed by $2 \mathrm{ml}$ of a $5 \%(\mathrm{w} / \mathrm{v}, 50 \mathrm{~g} / \mathrm{l}$ in TNE) sucrose solution on ice. The samples were centrifuged for $8 \mathrm{~h}$ at $268000 \mathrm{~g}$ at $4^{\circ} \mathrm{C}$ in an Optima Max ultracentrifuge MLS-50 rotor (Beckham Coulter). Based on previous experiments described later, the lipid-raft material $(1 \mathrm{ml})$ was collected from the 5/30\% glucose interface. Ice-cold TNE solution was added to raft fractions centrifuged at $268000 \mathrm{~g}$ for $30 \mathrm{~min}$ to pellet and concentrate the rafts.

Initial experiments were conducted using four obese JCR:LA- $c p$ rats that were fed the control diet to confirm the isolation of lipid rafts. Six consecutive $800 \mu$ l samples were taken, starting at the top of the gradient and the fractions were stored at $-80^{\circ} \mathrm{C}$ until dot-blotting was performed. A bicinchoninic acid assay (Sigma-Aldrich) was used to determine the protein concentration in each raft fraction. Each fraction $(2 \mu \mathrm{g} / 10 \mu \mathrm{l})$ was dot-blotted onto a nitrocellulose membrane and antibodies directed against the positive raft marker, GM1 ganglioside (cholera toxin B-subunit conjugated with horseradish peroxidase; Sigma), and the negative 
raft marker, transferrin receptor (Zymogen Laboratories, Invitrogen, Burlington, ON, Canada), were used to confirm the isolation of lipid rafts. The GM1-ganglioside marker stained most strongly in the third fraction and the transferrin receptor stained most intensely in fractions 4-6 and least intensely in fractions 1-3 (Fig. 1).

Splenocyte phospholipid fatty acid composition. A modified Folch method was used to extract lipids from freshly isolated, unstimulated splenocytes and lipid rafts (fraction 3), as previously described ${ }^{(34)}$. For lipid extracted from whole cells, total phospholipids were separated on silica $G$ plates, as previously described $^{(35)}$, and visualised with 8-anilino-1-naphthalenesulfonic acid under ultraviolet light against the appropriate standards. FA methyl esters were prepared from splenocyte total phospholipids and from total lipid of lipid rafts ${ }^{(34)}$, and were separated by automated GLC (Varian 3800; Varian Instruments, Mississauga, ON, Canada) using a $100 \mathrm{~m} \mathrm{CP}$ Sil 88 fused capillary column (Varian Instruments), as described elsewhere ${ }^{(36)}$.

\section{Statistics}

Statistical analysis was conducted by one-way ANOVA using the SAS software statistical package (version 9.1; SAS Institute, Cary, NC, USA). All data were reported as means with their standard errors. Significant differences among groups
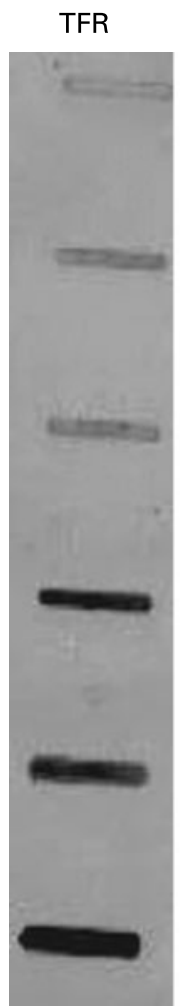

GM1

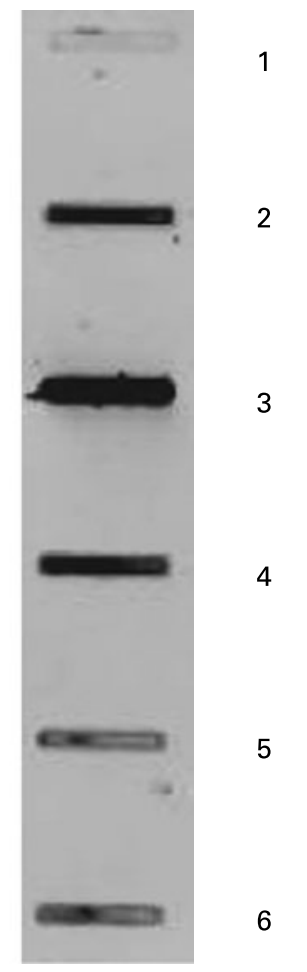

Fig. 1. Immunoblots characterising lipid rafts isolated from obese JCR : LA- $c p$ rats fed the control diet. GM1, positive raft marker; TFR (transferrin receptor), negative raft marker. Numbers represent the fraction number, where 1 is the top layer and 6 is the bottom layer. Fraction 3 represents the raft fraction and fractions 4-6 represent soluble membrane fractions. were determined by Duncan's multiple range test $(P<0.05)$ and all non-parametric data were log-transformed prior to running statistical analyses. The differences between groups with data that remained non-parametric after log-transforming were analysed using the Kruskal-Wallis/Wilcoxon test $(P<0 \cdot 05)$.

\section{Results}

\section{Feed intake, body-weight and spleen characteristics}

Obese rats had higher daily feed intake (33 (SEM 0.4) g/d v. 20 (SEM $0 \cdot 3) \mathrm{g} / \mathrm{d}, P<0 \cdot 05$ ), final body weight (592 (SEM 5) g $v$. 378 (SEM 4)g, $P<0.05)$ and spleen weight $(1165$ (SEM 40) mg $v .856$ (SEM 23) $\mathrm{mg}, P<0.05$ ) than lean rats. When adjusted for body weight (bwt), spleens of obese rats weighed less than lean rats $(1.98$ (SEM 0.06) $\mathrm{mg} / \mathrm{g}$ bwt $v$. 2.27 (SEM 0.06 ) $\mathrm{mg} / \mathrm{g}$ bwt, $P<0.05$ ), but the concentration of splenocytes per gram of spleen did not differ between lean and obese rats $(5.3 \quad$ (SEM 0.5$) \times 10^{8}$ cells $v$. 5.6 (SEM 0.4$) \times 10^{8}$ cells, $\left.P<0.05\right)$. Obese rats fed the LFO (556 (SEM 16)g) or HFO (561 (SEM $6 \mathrm{~g}$ ) diet had lower final body weights than the obese rats fed the control diet (592 (SEM $5 \mathrm{~g}$ ), $P<0.05$ ), but the change in body weight (76 (SEM 11) g, Ctl v. 85 (SEM 4)g, LFO v. 80 (SEM 5 )g, HFO) and feed intake did not differ (34 (SEM 0.6, LFO or 32 (SEM 0.3), HFO). Feeding FO did not alter spleen weight (LFO, 1930 (SEM 130)mg or HFO, 1910 (SEM 75) mg) or concentration of immune cells (LFO, 5.2 (SEM 0.6) $\times 10^{8}$ or HFO, $5.7($ SEM 1.0$\left.) \times 10^{8}\right)$ in the spleen.

\section{Fatty acid composition of splenocyte phospholipids}

Obese rats fed the control diet had a higher proportion of $16: 0,18: 1 n-9,20: 3 n-3,22: 5 n-3,22: 6 n-3$ and total MUFA and $n-3$ PUFA and a lower proportion of $18: 0,24: 1 n-9$ and $n-6: n-3$ PUFA ratio in splenocyte phospholipids, compared with the lean animals fed the same diet (Table 3). Obese animals fed either FO diet had a significantly higher proportion of $18: 1 n-9,20: 5 n-3,22: 5 n-3$ and total $n-3$ PUFA and lower proportion of $20: 4 n-6,24: 1 n-9$ and a lower $n-6: n-3$ PUFA ratio. Only the rats fed the LFO diet had a significantly higher proportion of $18: 2 n-6$, compared with the obese rats fed the control diet. Compared with the HFO diet, rats fed the LFO diet had a higher percentage of $20: 4 n-3$ and $n-6: n-3$ PUFA and a lower percentage of $20: 5 n-3$ and total $n$-3 PUFA. Feeding fish oil did not significantly change the proportion of $22: 6 n-3$ that was incorporated into the splenocyte PL membrane of the obese JCR:LA-cp rat (Table 3).

\section{Fatty acid composition of lipid rafts}

Obese rats fed either FO diet had a higher proportion of $18: 2 n-6,20: 5 n-3,22: 5 n-3$ and total $n-3$ PUFA and a lower proportion of $20: 4 n-6$ and $n-6: n-3$ PUFA ratio (Table 4). Only the rats fed the HFO diet had a higher proportion of cis9-16:1, cis-9-18:1 and 22:6n-3. Compared with the rats fed the HFO diet, the rats fed the LFO had a higher proportion of $18: 0$ and a lower percentage of cis-11-18:1,20:5n-3, total MUFA, total $n-3$ PUFA and a lower $n-6: n-3$ PUFA ratio (Table 4). 
Table 3. Fatty acid composition of splenocyte phospholipids in lean rats fed the control (Ctl) diet and obese rats fed the diet control (Ctl), low fish oil (LFO) or high fish oil (HFO) diet*

(Mean values with their standard errors for ten rats per group for the obese rats and five rats per group for the lean rats)

\begin{tabular}{|c|c|c|c|c|c|c|c|c|}
\hline & \multicolumn{8}{|c|}{ Group } \\
\hline & \multicolumn{2}{|c|}{ Lean Ctl } & \multicolumn{2}{|c|}{ Obese Ctl } & \multicolumn{2}{|c|}{ LFO } & \multicolumn{2}{|c|}{ HFO } \\
\hline & Mean & SEM & Mean & SEM & Mean & SEM & Mean & SEM \\
\hline $14: 0$ & 0.31 & 0.09 & 0.36 & 0.04 & 0.39 & 0.04 & 0.41 & 0.03 \\
\hline $16: 0$ & $23^{a}$ & 1 & $26^{b}$ & 1 & $26^{b}$ & 1 & $26^{b}$ & 1 \\
\hline $18: 0$ & $30^{a}$ & 1 & $23^{b}$ & 1 & $23^{b}$ & 1 & $22^{\mathrm{b}}$ & 1 \\
\hline $18: 1 n-9$ & $6.9^{b}$ & 0.3 & $7 \cdot 6^{\mathrm{b}}$ & 0.6 & $8.4^{\mathrm{a}}$ & 0.2 & $8.9^{\mathrm{a}}$ & 0.1 \\
\hline $18: 1 n-7$ & $1.6^{\mathrm{b}}$ & 0.0 & $2 \cdot 8^{\mathrm{a}}$ & 0.0 & $2.9^{a}$ & 0.1 & $3.0^{\mathrm{a}}$ & 0.1 \\
\hline $18: 2 n-6$ & $8 \cdot 1^{\mathrm{b}}$ & 0.7 & $8.0^{\mathrm{b}}$ & 0.4 & $9 \cdot 4^{\mathrm{b}}$ & 0.3 & $9 \cdot 0^{\mathrm{ab}}$ & 0.3 \\
\hline $18: 3 n-3$ & $0.38^{b}$ & 0.04 & $0.43^{\mathrm{ab}}$ & 0.01 & $0.49^{a}$ & 0.02 & $0.44^{\mathrm{ab}}$ & 0.02 \\
\hline $20: 3 n-6$ & 0.86 & $0 \cdot 17$ & 0.61 & 0.10 & 0.58 & 0.07 & 0.63 & 0.10 \\
\hline $20: 3 n-3$ & $0.58^{\mathrm{C}}$ & 0.07 & $1.4^{\mathrm{ab}}$ & 0.1 & $1.5^{\mathrm{a}}$ & 0.1 & $1.2^{\mathrm{b}}$ & 0.1 \\
\hline $22: 1 n-9$ & $0.20^{\mathrm{a}}$ & 0.06 & $0.43^{\mathrm{ab}}$ & 0.07 & $0.31^{b}$ & 0.05 & $0.26^{\mathrm{b}}$ & 0.05 \\
\hline $20: 4 n-6$ & $20^{\mathrm{a}}$ & 2 & $18^{\mathrm{a}}$ & 1 & $13^{\mathrm{b}}$ & 1 & $11^{\mathrm{b}}$ & 0 \\
\hline $20: 5 n-3$ & $0.1^{\mathrm{c}}$ & 0.0 & $0.7^{\mathrm{c}}$ & 0.2 & $2 \cdot 1^{\mathrm{b}}$ & 0.2 & $3.5^{a}$ & 0.1 \\
\hline $24: 0$ & 0.88 & 0.18 & 0.85 & 0.12 & 0.80 & 0.12 & 0.94 & 0.14 \\
\hline $22: 3 n-3$ & 0.70 & $0 \cdot 10$ & 0.75 & 0.15 & 0.82 & 0.14 & 0.93 & 0.14 \\
\hline $24: 1 n-9$ & $2 \cdot 4^{\mathrm{a}}$ & 0.2 & $1 \cdot 3^{\mathrm{b}}$ & 0.0 & $0.58^{\mathrm{c}}$ & 0.05 & $0.42^{c}$ & 0.04 \\
\hline $22: 4 n-6$ & $0 \cdot 26^{a}$ & 0.02 & $0.23^{\mathrm{ab}}$ & 0.02 & $0.23^{\mathrm{ab}}$ & 0.04 & $0 \cdot 16^{\mathrm{b}}$ & 0.02 \\
\hline $22: 5 n-3$ & $0.85^{\mathrm{c}}$ & 0.08 & $2 \cdot 2^{\mathrm{b}}$ & 0.3 & $3.5^{\mathrm{a}}$ & 0.4 & $4 \cdot 4^{\mathrm{a}}$ & 0.7 \\
\hline $22: 6 n-3$ & $1.0^{\mathrm{b}}$ & 0.1 & $2 \cdot 3^{a}$ & 0.2 & $2 \cdot 6^{a}$ & 0.3 & $2.9^{a}$ & 0.3 \\
\hline MUFA & $12^{\mathrm{b}}$ & 0 & $13^{\mathrm{a}}$ & 0 & $13^{a}$ & 0 & $14^{a}$ & 0 \\
\hline SFA & 55 & 2 & 51 & 1 & 51 & 1 & 50 & 1 \\
\hline PUFA & 34 & 3 & 35 & 2 & 34 & 2 & 35 & 1 \\
\hline PUFA:SFA & 0.61 & 0.07 & 0.70 & 0.05 & 0.67 & 0.05 & 0.71 & 0.03 \\
\hline$n-6$ PUFA & $31^{a}$ & 3 & $30^{\mathrm{ab}}$ & 1 & $27^{\mathrm{b}}$ & 1 & $26^{\mathrm{b}}$ & 1 \\
\hline$n-3$ PUFA & $2 \cdot 7^{d}$ & 0.1 & $5 \cdot 5^{\mathrm{c}}$ & 0.4 & $7.5^{\mathrm{b}}$ & 0.6 & $9 \cdot 4^{\mathrm{a}}$ & 0.4 \\
\hline$n-6: n-3$ PUFA & $11^{\mathrm{a}}$ & 1.3 & $5 \cdot 5^{\mathrm{b}}$ & 0.3 & $3.7^{\mathrm{c}}$ & 0.2 & $2 \cdot 8^{\mathrm{C}}$ & 0.1 \\
\hline
\end{tabular}

SFA, sum of SFA; MUFA, sum of MUFA; $n-6$ PUFA, sum of $n-6$ PUFA; $n-3$ PUFA, sum of $n-3$ PUFA.

$a, b, c$ Means within the same row that do not share a common letter are significantly different $(P<0 \cdot 05)$.

*The relative proportions of fatty acids from $12: 0$ to $24: 1 n-9$ were measured in the whole splenocyte membrane, but only the major fatty acids are reported.

\section{Phenotype of splenocytes}

Obese rats fed the control diet had a higher proportion of $\mathrm{CD} 3+\mathrm{CD} 4+$ and $\mathrm{CD} 11 \mathrm{~b} / \mathrm{c}+\mathrm{OX} 6-$, but a lower proportion of CD4+CD25+, CD11b/c+OX6+ and OX12+ (B-cells) splenocytes compared with lean rats fed the control diet (Table 5). Obese rats fed the FO diet had a higher proportion of $\mathrm{CD} 3+, \mathrm{CD} 3+\mathrm{CD} 4+, \mathrm{CD} 4+\mathrm{CD} 28+, \mathrm{CD} 4+\mathrm{CD} 28-$ and $\mathrm{CD} 11 \mathrm{~b} / \mathrm{c}+\mathrm{OX} 6$ - splenocytes, but only those rats fed the LFO diet had a higher proportion of CD4+CD25+ splenocytes and only the rats fed the HFO diet had a lower proportion of $\mathrm{CD} 11 \mathrm{~b} / \mathrm{c}+\mathrm{OX} 6+($ Table 5).

\section{Cytokine production}

Splenocytes of obese rats fed the control diet produced less mitogen-stimulated IFN- $\gamma$ (ConA, bacterial lipopolysaccharide and PWM), less LPS-stimulated IL-1 $\beta$ and less ConAstimulated IL-10 compared with lean rats fed the control diet (Figs. 2-4). Unstimulated splenocytes of obese rats fed the control diet produced less IL-6 (26 (SEM 4) pg/ml v. 61 (SEM 20) pg/ml) and IL-10 (348 (SEM 23) pg/ml v. 499 (SEM 86) $\mathrm{pg} / \mathrm{ml}$ ) than lean rats fed the control diet. IL-2, IL-4 or IL-10 (LPS or PWM stimulated; Figs. 2-4) or unstimulated TNF- $\alpha$ or IL-1 $\beta$ (data not shown) production did not differ between the lean and obese rats.

Feeding either FO diet to obese rats resulted in lower production of IL-1 $\beta$ (LPS or PWM stimulated), IL-10
(PWM stimulated), IFN- $\gamma$ (PWM and ConA stimulated) and IL-4 (ConA stimulated) compared with obese rats fed the control diet (Figs. 2-4). Obese rats fed the LFO diet had lower LPS-stimulated IFN- $\gamma$ production and lower IL-10 (236 (SEM 54) pg/ml v. 348 (SEM 23) pg/ml) production by unstimulated splenocytes. Obese rats fed the HFO diet had higher ConA-stimulated IL-10 production compared with obese control rats and lower LPS-stimulated IL-1 $\beta$ compared with obese rats fed the LFO diet. Feeding FO to obese rats did not alter IL-2 or IL-6 (Figs. 2-4) production or unstimulated TNF- $\alpha$ or IL-1 $\beta$ (data not shown).

\section{Haptoglobin}

The concentration of serum haptoglobin in either the LFO-fed rats $(1.6($ SEM $0 \cdot 1) \mathrm{mg} / \mathrm{ml})$ or HFO-fed rats $(1.6($ SEM $0 \cdot 1) \mathrm{mg} / \mathrm{ml})$ did not differ from obese Ctl rats $(1.7 \quad($ SEM 0.1$) \mathrm{mg} / \mathrm{ml})$ $(P<0.05)$.

\section{Discussion}

Immune dysfunction in the JCR:LA-cp rat

The present preliminary study demonstrated altered immune responses in the JCR:LA-cp rat, an established model of the metabolic syndrome. In comparison with lean rats, obese rats have a lower inflammatory response (defined by IL-6 production) in the unstimulated condition and a lower 
Table 4. Splenocyte fatty acid composition of total lipid rafts from obese JCR:LA- $c p$ rats fed the control (Ctl), low fish oil (LFO) or high fish oil (HFO) diet ${ }^{\star}$

(Mean values with their standard errors for nine rats per group)

\begin{tabular}{|c|c|c|c|c|c|c|}
\hline & \multicolumn{6}{|c|}{ Group } \\
\hline & \multicolumn{2}{|c|}{ Obese Ctl } & \multicolumn{2}{|c|}{ LFO } & \multicolumn{2}{|c|}{$\mathrm{HFO}$} \\
\hline & Mean & SEM & Mean & SEM & Mean & SEM \\
\hline $14: 0$ & 0.79 & 0.04 & 0.83 & 0.07 & 0.94 & 0.08 \\
\hline $16: 0$ & 37 & 1 & 37 & 1 & 37 & 1 \\
\hline $18: 0$ & $27^{\mathrm{ab}}$ & 1 & $29^{a}$ & 1 & $26^{\mathrm{b}}$ & 1 \\
\hline $18: 1 n-9$ & $5 \cdot 1^{b}$ & 0.1 & $5 \cdot 7^{\mathrm{b}}$ & 0.4 & $6 \cdot 9^{\mathrm{a}}$ & 0.4 \\
\hline $18: 1 n-7$ & $2 \cdot 2^{\mathrm{ab}}$ & 0.1 & $2 \cdot 1^{\mathrm{b}}$ & 0.1 & $2 \cdot 4^{a}$ & 0.1 \\
\hline $18: 2 n-6$ & $3 \cdot 7^{b}$ & 0.2 & $4 \cdot 5^{\mathrm{a}}$ & 0.3 & $4 \cdot 5^{\mathrm{a}}$ & 0.3 \\
\hline $18: 3 n-3$ & 0.35 & 0.01 & 0.37 & 0.02 & 0.38 & 0.02 \\
\hline $20: 3 n-6$ & 0.68 & 0.05 & 0.62 & 0.06 & 0.60 & 0.06 \\
\hline $20: 3 n-3$ & 1.4 & $0 \cdot 1$ & 1.5 & 0.1 & 1.3 & 0.1 \\
\hline $20: 4 n-6$ & $7 \cdot 0^{\mathrm{a}}$ & 0.4 & $4.9^{b}$ & 0.4 & $4 \cdot 6^{\mathrm{b}}$ & 0.4 \\
\hline $20: 5 n-3$ & $0 \cdot 17^{c}$ & 0.02 & $0.64^{b}$ & 0.06 & $1 \cdot 3^{\mathrm{a}}$ & 0.15 \\
\hline $24: 1 n-9$ & $2 \cdot 6$ & $0 \cdot 2$ & $2 \cdot 3$ & 0.2 & $2 \cdot 6$ & 0.2 \\
\hline $22: 4 n-6$ & $2 \cdot 1$ & 0.2 & 1.7 & 0.2 & $2 \cdot 1$ & 0.2 \\
\hline $22: 5 n-3$ & $0.82^{\mathrm{c}}$ & 0.10 & $1 \cdot 3^{\mathrm{b}}$ & 0.1 & $1.9^{\mathrm{a}}$ & 0.2 \\
\hline $22: 6 n-3$ & $0.68^{b}$ & 0.06 & $0.69^{b}$ & 0.10 & $1.0^{\mathrm{a}}$ & 0.1 \\
\hline MUFA & $12^{\mathrm{ab}}$ & 1 & $12^{b}$ & 1 & $14^{\mathrm{a}}$ & 1 \\
\hline SFA & 67 & 1 & 69 & 2 & 65 & 2 \\
\hline PUFA & 17 & 1 & 16 & 1 & 18 & 1 \\
\hline PUFA:SFA & 0.26 & 0.02 & 0.24 & 0.02 & 0.28 & 0.03 \\
\hline$n-6$ PUFA & 14 & 1 & 12 & 1 & 13 & 1 \\
\hline$n-3$ PUFA & $3 \cdot 4^{b}$ & 0.2 & $4 \cdot 5^{\mathrm{b}}$ & 0.3 & $5 \cdot 9^{\mathrm{a}}$ & 0.5 \\
\hline$n-6: n-3$ PUFA & $4 \cdot 2^{\mathrm{a}}$ & 0.2 & $2 \cdot 7^{\mathrm{b}}$ & $0 \cdot 1$ & $2 \cdot 1^{\mathrm{c}}$ & 0.1 \\
\hline
\end{tabular}

SFA, sum of SFA; MUFA, sum of MUFA; $n-6$ PUFA, sum of $n-6$ PUFA; $n-3$ PUFA, sum of $n-3$ PUFA.

$a, b, c$ Means within the same row that do not share a common letter are significantly different $(P<0.05)$.

${ }^{*}$ The relative proportions of fatty acids from $12: 0$ to $24: 1 n-9$ were measured, but only the major fatty acids are reported. production of inflammatory cytokines (IL-1 $\beta$ and IFN- $\gamma$ ) with mitogen stimulation. The lower production of LPS-stimulated IFN- $\gamma$ is consistent with our previous findings in Zucker $\mathrm{fa} / \mathrm{fa}$ rats $^{(31)}$, a study in $o b / o b$ mice lymph nodes (37) and a study using diet-induced obese (DIO) mice ${ }^{(38)}$. However, ConAstimulated IFN- $\gamma$ production was also lower in obese rats. We and other groups have reported higher T-cell mitogeninduced IFN- $\gamma$ production in splenocytes of $f a / f a$ Zucker rats $^{(31)}$. Similar to our observation in the present study that unstimulated splenocytes of obese rats produced less IL-6, Lamas et al. (2004) reported lower IL-6 mRNA levels in basal-state splenocytes of DIO rats ${ }^{(39)}$. In obese human subjects, the effects of obesity on ex vivo mitogen-stimulated cytokine production are limited to two studies. Although one study has reported that blood mononuclear cells of obese individuals produce more $\mathrm{TNF}-\alpha$ in response to bacterial lipopolysaccharide ${ }^{(12)}$, a study conducted in morbidly obese patients reported significantly less production of monocyte chemoattractant protein-1 (MCP-1) and IFN- $\gamma$ in response to bacterial lipopolysaccharide and PMAI (phorbol-12-myristate 13 -acetate + ionomycin) stimulation $^{(40)}$. The present study suggests that inflammatory cytokine production in the JCR:LA- $c p$ rat may better represent morbid obesity in human subjects. However, despite the lower n-6:n-3 PUFA ratio in membranes and a leptin receptor defect, IL-2 production (a measure of $\mathrm{T}$-cell proliferative response) after mitogen stimulation was not different between obese and lean JCR:LA- $c p$ rats, suggesting that unlike Zucker $f a / f a$ rats and genetic and diet-induced rodent models of obesity $^{(31,41,42-46)}$, mitogen-induced proliferation by splenocytes does not appear to be impaired in obese JCR:LA-cp rats. Presently, mitogen-stimulated IL-2 production in obese individuals has not been measured ex vivo. However, two

Table 5. Splenocyte phenotypes of lean JCR:LA-cp rats fed the Ctl diet or obese JCR:LA-cp rats fed the control (CtI) diet or obese JCR:LA- $c p$ rats fed the Ctl, low fish oil (LFO) or high fish oil (HFO) diet ${ }^{\star}$

(Mean values with their standard errors for ten rats per group for the obese rats and five rats per group for the lean rats)

\begin{tabular}{|c|c|c|c|c|c|c|c|c|}
\hline & \multicolumn{2}{|c|}{ Lean Ctl } & \multicolumn{2}{|c|}{ Obese Ctl } & \multicolumn{2}{|c|}{ LFO } & \multicolumn{2}{|c|}{$\mathrm{HFO}$} \\
\hline & Mean & SEM & Mean & SEM & Mean & SEM & Mean & SEM \\
\hline CD3+ & $46^{\mathrm{ab}}$ & 1 & $44^{\mathrm{b}}$ & 1 & $48^{a}$ & 1 & $49^{a}$ & 2 \\
\hline CD4+ & $37^{c}$ & 0 & $42^{b}$ & 1 & $46^{\mathrm{ab}}$ & 1 & $46^{a}$ & 1 \\
\hline CD3+CD4+ & $33^{b}$ & 0 & $33^{\mathrm{b}}$ & 1 & $38^{a}$ & 1 & $37^{\mathrm{a}}$ & 2 \\
\hline CD8+ & 16 & 1 & 15 & 1 & 15 & 0 & 15 & 1 \\
\hline CD3+CD8+ & 13 & 1 & 13 & 2 & 13 & 0 & 12 & 1 \\
\hline CD4+CD25+ & $8 \cdot 8^{a}$ & 0.5 & $5 \cdot 9^{b}$ & 0.8 & $9 \cdot 1^{a}$ & 0.5 & $6.9^{\mathrm{ab}}$ & 0.6 \\
\hline CD4+CD25- & $44^{\mathrm{a}}$ & 2 & $41^{\mathrm{ab}}$ & 1 & $39^{\mathrm{b}}$ & 1 & $40^{\mathrm{b}}$ & 1 \\
\hline CD8+CD25+ & 3.6 & 0.5 & $2 \cdot 8$ & 0.5 & 3.5 & 0.4 & $2 \cdot 4$ & 0.5 \\
\hline CD8+CD25 - & $17^{a}$ & 1 & $15^{\mathrm{ab}}$ & 1 & $13^{\mathrm{b}}$ & 1 & $15^{a b}$ & 1 \\
\hline $\mathrm{CD} 4+\mathrm{CD} 28+$ & & & $44^{\mathrm{b}}$ & 1 & $50^{\mathrm{a}}$ & 1 & $48^{\mathrm{a}}$ & 1 \\
\hline $\mathrm{CD} 8+\mathrm{CD} 28+$ & & & 11 & 1 & 11 & 1 & $9 \cdot 3$ & 0 \\
\hline CD4+CD28- & & & $6 \cdot 3^{\mathrm{a}}$ & 0.4 & $4 \cdot 4^{\mathrm{b}}$ & 0.4 & $4 \cdot 8^{\mathrm{b}}$ & 0.3 \\
\hline CD8+CD28- & & & 4.4 & 0.3 & 4.7 & 0.6 & $4 \cdot 2$ & 0.4 \\
\hline $\mathrm{CD} 11 \mathrm{~b} / \mathrm{c}+\mathrm{OX} 6+$ & $11^{\mathrm{a}}$ & 0.5 & $6 \cdot 7^{\mathrm{b}}$ & 0.9 & $6 \cdot 6^{\mathrm{b}}$ & 0.6 & $4.0^{\mathrm{C}}$ & 0.4 \\
\hline $\mathrm{CD} 11 \mathrm{~b} / \mathrm{c}+\mathrm{OX} 6-$ & $4 \cdot 2^{c}$ & 0.4 & $5 \cdot 8^{b}$ & 0.4 & $7 \cdot 2^{\mathrm{a}}$ & 0.5 & $7 \cdot 4^{\mathrm{a}}$ & 0.4 \\
\hline $\mathrm{CD} 11 \mathrm{~b} / \mathrm{c}+$ & $12^{\mathrm{ab}}$ & 1 & $12^{\mathrm{ab}}$ & 1 & $14^{\mathrm{a}}$ & 1 & $11^{\mathrm{b}}$ & 1 \\
\hline OX6+ & $38^{\mathrm{a}}$ & 3 & $36^{\mathrm{ab}}$ & 1 & $32^{\mathrm{b}}$ & 2 & $31^{\mathrm{b}}$ & 1 \\
\hline OX12+ & $42^{a}$ & 2 & $37^{\mathrm{b}}$ & 1 & $35^{\mathrm{b}}$ & 1 & $36^{\mathrm{b}}$ & 1 \\
\hline
\end{tabular}

NM, not measured.

*The values are a proportion of the total gated cells as determined by immunofluorescence.

${ }^{a, b, c}$ Means within the same row that do not share a common letter are significantly different $(P<0.05)$. 


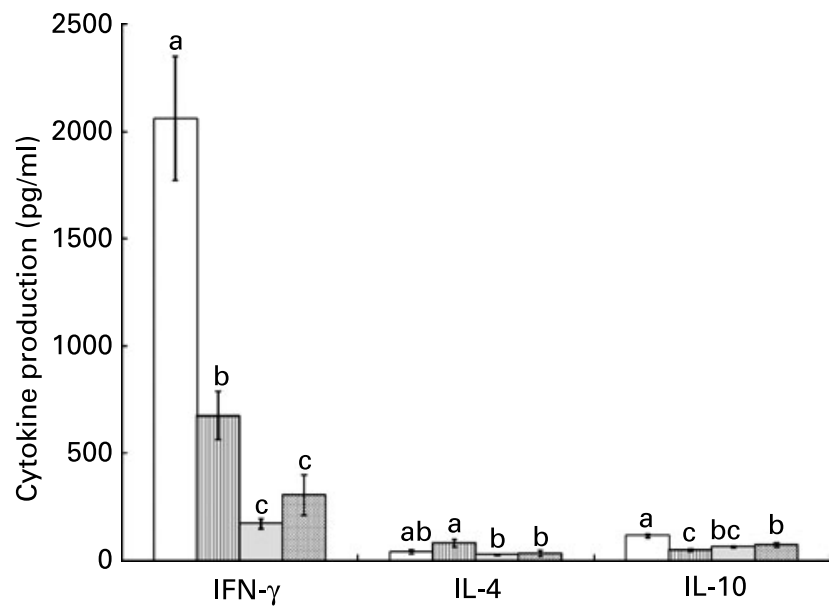

Fig. 2. Concanavalin $A(C o n A)$-stimulated splenocyte cytokine production in lean and obese JCR: LA- $c p$ rats fed the control (Ctl) diet and obese rats fed the low fish (LFO) or the high fish oil (HFO) diet. The bars represent means with their standard errors (ten per group for obese Ctl, LFO and HFO and five per group for lean $\mathrm{Ctl}$ ). ${ }^{\mathrm{a}, \mathrm{b}, \mathrm{c}}$ The bars not sharing a common letter are significantly different $(P<0.05)$. $\square$, Lean Ctl; 四, obese Ctl; $\square$, LFO; $\nabla$, HFO. ConA-stimulated IL-2 (1328 (SEM 79), $n$ 34), TNF- $\alpha$ (62 (SEM 7), $n$ 35) and IL-6 (180 (SEM 12), $n$ 35) were not statistically different among groups. IFN, interferon.

groups have reported that there was no difference in the percentage of PMAI-stimulated CD4+ cells that expressed IL-2 in obese children ${ }^{(47,48)}$. This suggests that the JCR:LA$\mathrm{cp}$ rat represents the mitogen-stimulated production of IL-2 observed in human obesity.

\section{Leptin receptor and immunity}

The JCR:LA- $c p$ rat expresses a dysfunctional form of the leptin receptor due to a single point mutation in the corpulent $(c p)$ or leptin receptor gene ${ }^{(49,50)}$. As a consequence, the extracellular domain of the leptin receptor is absent and thus obese $(\mathrm{cp} / \mathrm{cp}$ ) rats lack the ability to respond to leptin via the long form of

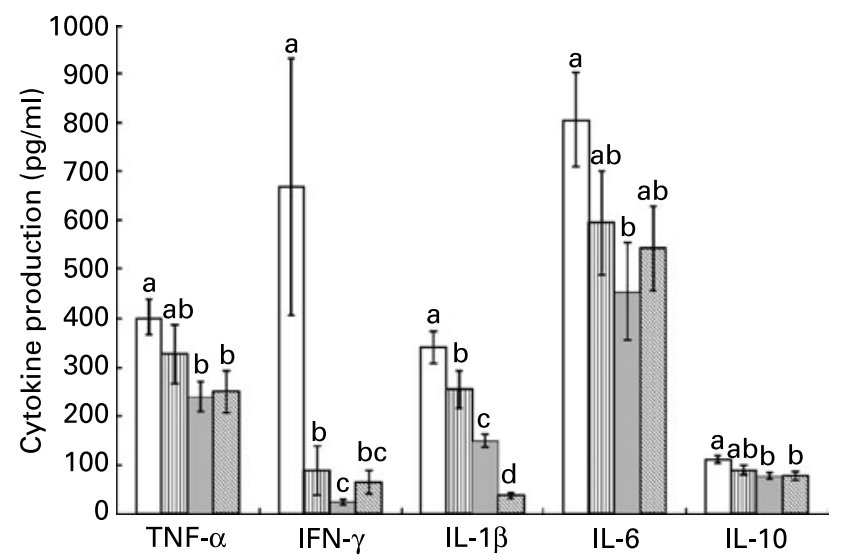

Fig. 3. Lipopolysaccharide-stimulated splenocyte cytokine production in lean and obese JCR:LA- $c p$ rats fed the control (Ctl) diet and obese rats fed the fish oil diet. The bars represent means with their standard errors (ten per group for obese, Ctl, low fish oil (LFO) and high fish oil (HFO) and five per group for lean $\mathrm{Ctl})$. ${ }^{\mathrm{a}, \mathrm{b}, \mathrm{c}, \mathrm{d}}$ The bars not sharing a common letter are signifi-

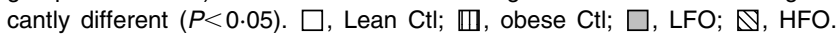
IFN, interferon.

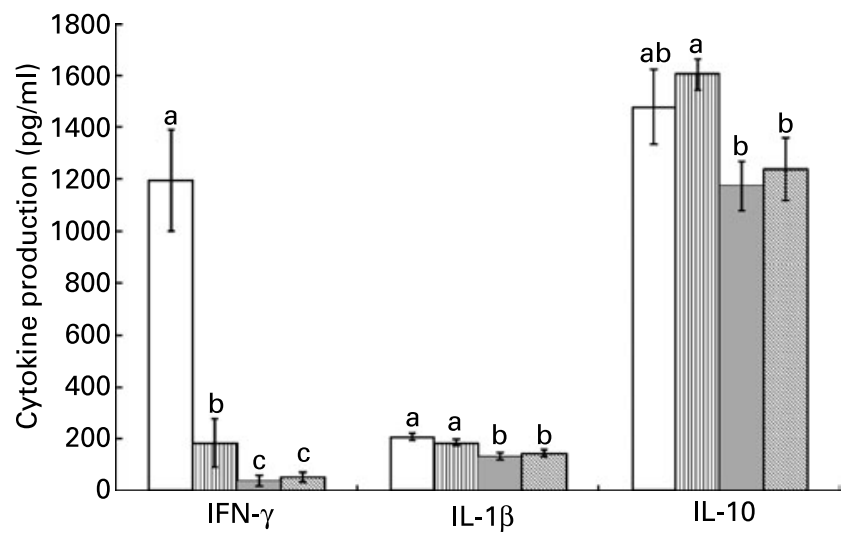

Fig. 4. Pokeweed mitogen (PWM)-stimulated splenocyte cytokine production in lean and obese JCR:LA- $c p$ rats fed the control (Ctl) diet and obese rats fed the fish oil diet. The bars represent means with their standard errors (ten per group for obese Ctl, low fish oil (LFO) and high fish oil (HFO) and five per group for lean $\mathrm{Ctl}) .{ }^{\mathrm{a}, \mathrm{b}, \mathrm{c}}$ The bars not sharing a common letter are signifi-

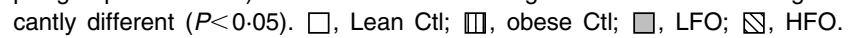
PWM-stimulated TNF- $\alpha$ (273 (SEM 22), $n$ 35), IL-2 (184 (SEM 15), $n$ 34) and IL-6 (289 (SEM 19), $n$ 34) were not statistically different among groups. IFN, interferon.

the leptin receptor $(\mathrm{Ob}-\mathrm{Rb})$. Recent evidence indicates that leptin has a significant role in immune cell function (37,51-56) and is expressed on several immune cell types, including macrophages and dendritic cells and T- and B-lymphocytes ${ }^{(54,57)}$. Researchers have identified leptin as a key regulator of the inflammatory response of both the innate and acquired immune systems ${ }^{(37,51-56)}$. Therefore, the absence of a functional leptin receptor signalling via the $\mathrm{Ob}-\mathrm{Rb}$ likely accounts, at least in part, for the impaired production of inflammatory mediators in splenocytes of the JCR:LA- $c p$ rat ${ }^{(58)}$. The present finding that ConA-stimulated IL-2 production is unaltered in obese JCR:LA- $c p$ rats is surprising in the light of evidence which suggests that leptin is critical for the proliferative response of CD4+T-lymphocytes, the prevention of T-lymphocyte apoptosis and the secretion of IL-2 (as reviewed by Matarese et al. ${ }^{(59)}$ ). This suggests that in this rodent model leptin is not critical for adequate IL-2 secretion, a measure of T-cell proliferation in mitogen-stimulated splenocytes.

\section{Effect of feeding fish oil on immune function in obese JCR:LA-cp rats}

Feeding fish oil reduced the production of inflammatory cytokines by splenocytes in this rodent model, without altering the proliferative response (measured by IL-2 production) of T-lymphocytes. It is interesting that despite normal IL-2 production, feeding EPA and DHA lowered both the Th1 (IFN- $\gamma$ ) and Th2 (IL-4) cytokines when JCR:LA-cp rat splenocytes were stimulated with a T-cell mitogen. It is difficult to ascertain if this finding is specific to this rodent model or reflective of the obese state, as few studies have examined the impact of fish oil on immune function in obese and/or insulin-resistant conditions. While we did not include a group of lean rats fed the FO diet, previous studies in non-obese rodents have shown that dietary $n-3$ PUFA suppress IL-2 production ${ }^{(60-63)}$. It has recently been postulated that $n-3$ PUFA lower both the Th1 and Th2 cytokine responses in other inflammatory disease 
states, which is consistent with our data (as reviewed by Calder \& Grimble $\left.{ }^{(16)}\right)$.

In addition to the effects on the adaptive immune system, feeding fish oil also resulted in a lower innate immune response as determined by ex vivo LPS-stimulated cytokine production. Feeding the higher level of EPA and DHA resulted in a significantly lower LPS-stimulated IL-1 $\beta$ production and higher ConA-stimulated IL-10, suggesting that the higher dose is more effective at suppressing the inflammatory response than the lower dose. It is well established in other inflammatory disease states that high doses of EPA and DHA can reduce the inflammatory response and improve disease pathology (as reviewed by Calder ${ }^{(17)}$ ). Consistent with studies feeding FO to overweight subjects ${ }^{(21-24)}$, the $n-3$ PUFA diets did not influence a serum marker of inflammation (haptoglobin). The HFO diet contained slightly higher levels of total MUFA compared with the Ctl diet. The changes in the MUFA content of the diet have been reported to alter immune function, but the differences in these studies far exceeded the $3 \%$ difference in the present study ${ }^{(64,65)}$.

\section{Effects of diet and obesity on lipid membrane composition}

The differences in PUFA composition of the PL membrane between lean and obese rats may have contributed to the lower production of inflammatory cytokines. Obese rats fed the control diet had a lower $n-6: n-3$ PUFA ratio due to a higher incorporation of total $n-3$ fatty acids, including DHA $(22: 6 n-3)$. The lower PL $n-6: n-3$ PUFA ratio agrees with our previous findings (31) and others using the $f a / f a$ Zucker rat ${ }^{(66,67)}$. It is well established that lowering the $n-6: n-3$ PUFA ratio in the membrane of immune cells can reduce the inflammatory response in both healthy and inflammatory states (as reviewed by Calder ${ }^{(17)}$ ). Obese JCR:LA- $c p$ rats had significant differences in the fatty acid composition of splenocyte phospholipids despite consuming the same diet as lean rats (Table 3), suggesting an abnormality in fatty acid metabolism.

Feeding fish oil further lowered the $n-6: n-3$ PUFA ratio in the splenocyte membrane of obese rats, due to both a higher content of EPA and DPA (docosapentaenoic acid, $22: 5 n-3$ ) and lower AA. Recently, it has been suggested that PUFAmediated alterations in immune cell function can be explained, in part, by the changes in the protein and lipid content and composition of lipid rafts (as reviewed by Ma et al. ${ }^{(68)}$ ). In the present study, compared with obese rats fed the control diet, obese rats fed the FO diet had significantly higher incorporation of linoleic acid, EPA and DPA and a lower proportion of AA and n-6:n-3 PUFA in lipid rafts isolated from the splenocyte. Only obese rats fed the HFO diet had a significantly higher percentage of DHA in the lipid component of splenocyte rafts. The present results suggest that there is a preferential incorporation of $n$-3 PUFA into the lipid-raft domains compared with the whole membrane when FO is fed. Relative to the whole membrane, there was a greater increase of EPA into the lipid raft when FO was fed $(76 \%$ and $265 \%$ greater for the LFO and HFO diets, respectively). Furthermore, in relation to the whole membrane, the incorporation of DHA into the lipid raft was $21 \%$ greater for rats fed the higher dose of fish oil. The significantly higher incorporation of DHA into the lipid raft of obese rats fed the HFO diet may have contributed to the finding that JCR:LA-cp rats fed the
HFO diet had a lower proportion of activated innate immune cells $(\mathrm{CD} 11 \mathrm{~b} / \mathrm{c}+\mathrm{OX} 6+$, non-B-cells expressing the MHC class II molecule). The major histocompatability complex (MHC) class II molecule has been shown to reside in membrane microdomains of dendritic cells and macrophages/monocytes ${ }^{(69-72)}$ and $n-3$ fatty acids can down-regulate the expression of the MHC II molecule on immune cells from healthy rodents ${ }^{(73)}$. Thus, it is possible that the significantly higher proportion of DHA in splenocyte lipid rafts of rats fed the HFO diet could have displaced the MHC class II molecule from the lipid-raft component of the splenocyte membrane and contributed to the lower inflammatory response (lower LPS-stimulated IL-1 $\beta$ ).

\section{Conclusion}

This is the first study to report that the JCR:LA-cp rat, a genetic rodent model of obesity and insulin resistance, has impaired immune responses. With the exception of IL-2 production, splenocytes of obese rats were poor responders to mitogen stimulation. There was lower mitogen-stimulated inflammatory cytokine production in these rats, which may be due to the higher proportion of $n$-3 PUFA in splenocyte PL membranes. Feeding fish oil to obese rats reduced mitogen-stimulated inflammatory cytokine production without affecting ConA-stimulated IL-2 production, possibly via modification to the fatty acid composition of the whole membrane and lipid raft. Furthermore, the HFO diet improved the inflammatory response to a greater extent than the lower FO diet (lower IL- $\beta$ and higher IL-10 production). The relatively higher incorporation of DHA into the lipid rafts of splenocyte membranes coincided with a reduced MHC class II molecule expression and lower IL-1 $\beta$ production.

\section{Acknowledgements}

There are no conflicts of interest. Funding for the present study was made possible in part by contributions from Dairy Farmers of Canada, the Natural Sciences and Engineering Research Council of Canada (NSERC), Alberta Livestock and Industry Development Fund (ALIDF) and the Alberta Diabetes Institute. M. R. R. held the Muttart/Collip Diabetes Studentship from the Muttart Diabetes and Research Training Centre, University of Alberta, Edmonton, Alberta, Canada. M. R. R. designed the experimental diets and performed all experimental assays, statistical analyses and wrote the manuscript with feedback from all authors. S. D. P. and C. J. F. were involved with experimental design and supported all stages with intellectual guidance. We wish to thank Susan Goruk and Marnie Newell for their excellent technical assistance and Kristina McNaughton and Sharon Sokolik for their exceptional care of the animals and assistance with the present study.

\section{References}

1. Warnberg $\mathbf{J} \&$ Marcos A (2008) Low-grade inflammation and the metabolic syndrome in children and adolescents. Curr Opin Lipidol 19, 11-15. 
2. Calle EE \& Kaaks R (2004) Overweight, obesity and cancer: epidemiological evidence and proposed mechanisms. Nat Rev Cancer 4, 579-591.

3. Pan SY, Johnson KC, Ugnat AM, et al. (2004) Association of obesity and cancer risk in Canada. Am J Epidemiol 159, 259-268.

4. Ridker PM, Buring JE, Shih J, et al. (1998) Prospective study of C-reactive protein and the risk of future cardiovascular events among apparently healthy women. Circulation 98, 731-733.

5. Ridker PM, Hennekens CH, Buring JE, et al. (2000) C-reactive protein and other markers of inflammation in the prediction of cardiovascular disease in women. $N$ Engl $J$ Med 342, 836-843.

6. Duncan BB, Schmidt MI, Pankow JS, et al. (2003) Low-grade systemic inflammation and the development of type 2 diabetes: the atherosclerosis risk in communities study. Diabetes 52, 1799-1805.

7. Falagas ME \& Kompoti M (2006) Obesity and infection. Lancet Infect Dis 6, 438-446.

8. Weber DJ, Rutala WA, et al. (1985) Obesity as a predictor of poor antibody response to hepatitis B plasma vaccine. $J$ Am Med Assoc 254, 3187-3189.

9. Simo MJ, Gaztambide GM, Fernandez MP, et al. (1996) Hepatitis B vaccine immunoresponsiveness in adolescents: a revaccination proposal after primary vaccination. Vaccine $\mathbf{1 4}$, 103-106.

10. Eliakim A, Schwindt C, Zaldivar F, et al. (2006) Reduced tetanus antibody titers in overweight children. Autoimmunity 39, $137-141$.

11. Tanaka S, Inoue S, Isoda F, et al. (1993) Impaired immunity in obesity: suppressed but reversible lymphocyte responsiveness. Int J Obes Relat Metab Disord 17, 631-636.

12. Tanaka S, Isoda F, Ishihara $\mathrm{Y}$, et al. (2001) T lymphopaenia in relation to body mass index and TNF-alpha in human obesity: adequate weight reduction can be corrective. Clin Endocrinol (Oxf) 54, 347-354.

13. Russell JC, Koeslag DG, Amy RM, et al. (1989) Plasma lipid secretion and clearance in hyperlipidemic JCR:LA-corpulent rats. Arteriosclerosis 9, 869-876.

14. Russell JC, Graham S \& Hameed M (1994) Abnormal insulin and glucose metabolism in the JCR:LA-corpulent rat. Metabolism 43, 538-543.

15. Dolphin PJ, Stewart B, Amy RM, et al. (1987) Serum lipids and lipoproteins in the atherosclerosis prone LA/N corpulent rat. Biochim Biophys Acta 919, 140-148.

16. Calder PC \& Grimble RF (2002) Polyunsaturated fatty acids, inflammation and immunity. Eur J Clin Nutr Suppl 3, 56, S14-S19.

17. Calder PC (2006) $n-3$ polyunsaturated fatty acids, inflammation, and inflammatory diseases. Am J Clin Nutr 83, 1505S-1519S.

18. Aguilera AA, Diaz GH, Barcelata ML, et al. (2004) Effects of fish oil on hypertension, plasma lipids, and tumor necrosis factor-alpha in rats with sucrose-induced metabolic syndrome. J Nutr Biochem 15, 350-357.

19. Guermouche B, Yessoufou A, Soulimane N, et al. (2004) n-3 fatty acids modulate T-cell calcium signaling in obese macrosomic rats. Obes Res 12, 1744-1753.

20. Khan NA, Yessoufou A, Kim M, et al. (2006) n-3 fatty acids modulate Th1 and Th2 dichotomy in diabetic pregnancy and macrosomia. J Autoimmun 26, 268-277.

21. Chan DC, Watts GF, Barrett PH, et al. (2002) Effect of atorvastatin and fish oil on plasma high-sensitivity C-reactive protein concentrations in individuals with visceral obesity. Clin Chem 48, 877-883.

22. Jellema A, Plat J \& Mensink RP (2004) Weight reduction, but not a moderate intake of fish oil, lowers concentrations of inflammatory markers and PAI-1 antigen in obese men during the fasting and postprandial state. Eur J Clin Invest 34, $766-773$.

23. Plat J, Jellema A, Ramakers J, et al. (2007) Weight loss, but not fish oil consumption, improves fasting and postprandial serum lipids, markers of endothelial function, and inflammatory signatures in moderately obese men. J Nutr 137, 2635-2640.

24. Browning LM, Krebs JD, Moore CS, et al. (2007) The impact of long chain $n-3$ polyunsaturated fatty acid supplementation on inflammation, insulin sensitivity and CVD risk in a group of overweight women with an inflammatory phenotype. Diabetes Obes Metab 9, 70-80.

25. Brown DA \& London E (1998) Functions of lipid rafts in biological membranes. Anпи Rev Cell Dev Biol 14, 111-136.

26. Dykstra M, Cherukuri A, Sohn HW, et al. (2003) Location is everything: lipid rafts and immune cell signaling. Annu Rev Immunol 21, 457-481.

27. Shaikh SR \& Edidin MA (2006) Membranes are not just rafts. Chem Phys Lipids 144, 1-3.

28. Dolphin PJ (1981) Serum and hepatic nascent lipoproteins in normal and hypercholesterolemic rats. J Lipid Res 22, 971-989.

29. Reimer RA \& Russell JC (2008) Glucose tolerance, lipids, and GLP-1 secretion in JCR:LA-cp rats fed a high protein fiber diet. Obesity (Silver Spring) 16, 40-46.

30. Field CJ, Wu G, Metroz-Dayer MD, et al. (1990) Lactate production is the major metabolic fate of glucose in splenocytes and is altered in spontaneously diabetic BB rats. Biochem $J$ 272, 445-452.

31. Ruth MR, Taylor CG, Zahradka P, et al. (2008) Abnormal immune responses in fa/fa Zucker rats and effects of feeding conjugated linoleic acid. Obesity (Silver Spring) 16, 1770-1779.

32. Field CJ, Thomson CA, Van Aerde JE, et al. (2000) Lower proportion of CD45R0 + cells and deficient interleukin-10 production by formula-fed infants, compared with human-fed, is corrected with supplementation of long-chain polyunsaturated fatty acids. J Pediatr Gastroenterol Nutr 31, 291-299.

33. Schley PD, Brindley DN \& Field CJ (2007) (n-3) PUFA alter raft lipid composition and decrease epidermal growth factor receptor levels in lipid rafts of human breast cancer cells. J Nutr 137, 548-553.

34. Field CJ, Ryan EA, Thomson AB, et al. (1988) Dietary fat and the diabetic state alter insulin binding and the fatty acyl composition of the adipocyte plasma membrane. Biochem $J \mathbf{2 5 3}$, 417-424.

35. Layne KS, Goh YK, Jumpsen JA, et al. (1996) Normal subjects consuming physiological levels of 18:3(n-3) and 20:5(n-3) from flaxseed or fish oils have characteristic differences in plasma lipid and lipoprotein fatty acid levels. J Nutr $\mathbf{1 2 6}$, 2130-2140.

36. Cruz-Hernandez C, Deng Z, Zhou J, et al. (2004) Methods for analysis of conjugated linoleic acids and trans-18:1 isomers in dairy fats by using a combination of gas chromatography, silver-ion thin-layer chromatography/gas chromatography, and silver-ion liquid chromatography. $J$ AOAC Int 87, $545-562$.

37. Busso N, So A, Chobaz-Peclat V, et al. (2002) Leptin signaling deficiency impairs humoral and cellular immune responses and attenuates experimental arthritis. J Immunol 168, 875-882.

38. Katagiri K, Arakawa S, Kurahashi R, et al. (2007) Impaired contact hypersensitivity in diet-induced obese mice. J Dermatol Sci 46, 117-126.

39. Lamas O, Martinez JA \& Marti A (2004) Decreased splenic mRNA expression levels of TNF-alpha and IL-6 in diet-induced obese animals. $J$ Physiol Biochem 60, 279-283.

40. Fontana L, Eagon JC, Colonna M, et al. (2007) Impaired mononuclear cell immune function in extreme obesity is corrected by weight loss. Rejuvenation Res 10, 41-46. 
41. Mito N, Hosoda T, Kato C, et al. (2000) Change of cytokine balance in diet-induced obese mice. Metabolism 49, 1295-1300.

42. Lamas O, Martinez JA \& Marti AT-helper (2002) lymphopenia and decreased mitogenic response in cafeteria diet-induced obese rats. Nutr Res 22, 497-506.

43. Moriguchi S, Kato M, Sakai K, et al. (1998) Exercise training restores decreased cellular immune functions in obese Zucker rats. J Appl Physiol 84, 311-317.

44. Tanaka S, Isoda F, Yamakawa T, et al. (1998) T lymphopenia in genetically obese rats. Clin Immunol Immunopathol 86, 219-225.

45. Lamas O, Martinez JA \& Marti A (2003) Effects of a beta3adrenergic agonist on the immune response in diet-induced (cafeteria) obese animals. J Physiol Biochem 59, 183-191.

46. Mito N, Kaburagi T, Yoshino H, et al. (2006) Oral-tolerance induction in diet-induced obese mice. Life Sci 79, 1056-1061.

47. Pacifico L, Di RL, Anania C, et al. (2006) Increased T-helper interferon-gamma-secreting cells in obese children. Eur J Endocrinol 154, 691-697.

48. Svec P, Vasarhelyi B, Paszthy B, et al. (2007) Do regulatory T cells contribute to Th1 skewness in obesity? Exp Clin Endocrinol Diabetes 115, 439-443.

49. Russell JC \& Amy RM (1986) Myocardial and vascular lesions in the LA/N-corpulent rat. Can J Physiol Pharmacol 64, $1272-1280$.

50. Russell JC \& Amy RM (1986) Early atherosclerotic lesions in a susceptible rat model. The LA/N-corpulent rat. Atherosclerosis 60, 119-129.

51. Loffreda S, Yang SQ, Lin HZ, et al. (1998) Leptin regulates proinflammatory immune responses. FASEB $J$ 12, 57-65.

52. Martin-Romero C, Santos-Alvarez J, Goberna R, et al. (2000) Human leptin enhances activation and proliferation of human circulating T lymphocytes. Cell Immunol 199, 15-24.

53. Lord GM, Matarese G, Howard JK, et al. (1998) Leptin modulates the $\mathrm{T}$-cell immune response and reverses starvationinduced immunosuppression. Nature 394, 897-901.

54. Mattioli B, Straface E, Quaranta MG, et al. (2005) Leptin promotes differentiation and survival of human dendritic cells and licenses them for Th1 priming. J Immunol 174, 6820-6828.

55. Matarese G, Di GA, Sanna V, et al. (2001) Requirement for leptin in the induction and progression of autoimmune encephalomyelitis. J Immunol 166, 5909-5916.

56. Siegmund B, Sennello JA, Jones-Carson J, et al. (2004) Leptin receptor expression on $\mathrm{T}$ lymphocytes modulates chronic intestinal inflammation in mice. Gut 53, 965-972.

57. Papathanassoglou E, El-Haschimi K, Li XC, et al. (2006) Leptin receptor expression and signaling in lymphocytes: kinetics during lymphocyte activation, role in lymphocyte survival, and response to high fat diet in mice. J Immunol 176, $7745-7752$.

58. Wu-Peng XS, Chua SC Jr, Okada N, et al. (1997) Phenotype of the obese Koletsky (f) rat due to Tyr763Stop mutation in the extracellular domain of the leptin receptor (Lepr): evidence for deficient plasma-to-CSF transport of leptin in both the Zucker and Koletsky obese rat. Diabetes 46, 513-518.

59. Matarese G, Moschos S \& Mantzoros CS (2005) Leptin in immunology. J Immunol 174, 3137-3142.

60. Jolly CA, Jiang YH, Chapkin RS, et al. (1997) Dietary (n-3) polyunsaturated fatty acids suppress murine lymphoproliferation, interleukin-2 secretion, and the formation of diacylglycerol and ceramide. J Nutr 127, 37-43.

61. Wallace FA, Miles EA, Evans C, et al. (2001) Dietary fatty acids influence the production of Th1- but not Th2-type cytokines. J Leukoc Biol 69, 449-457.

62. Arrington JL, McMurray DN, Switzer KC, et al. (2001) Docosahexaenoic acid suppresses function of the CD28 costimulatory membrane receptor in primary murine and Jurkat T cells. J Nutr 131, 1147-1153.

63. Fan YY, Ly LH, Barhoumi R, et al. (2004) Dietary docosahexaenoic acid suppresses $\mathrm{T}$ cell protein kinase $\mathrm{C}$ theta lipid raft recruitment and IL-2 production. J Immunol 173, 6151-6160.

64. Jeffery NM, Cortina M, Newsholme EA, et al. (1997) Effects of variations in the proportions of saturated, monounsaturated and polyunsaturated fatty acids in the rat diet on spleen lymphocyte functions. Br J Nutr 77, 805-823.

65. Yaqoob P, Newsholme EA \& Calder PC (1994) The effect of dietary lipid manipulation on rat lymphocyte subsets and proliferation. Immunology 82, 603-610.

66. Phinney SD, Tang AB, Thurmond DC, et al. (1993) Abnormal polyunsaturated lipid metabolism in the obese Zucker rat, with partial metabolic correction by gamma-linolenic acid administration. Metabolism 42, 1127-1140.

67. Guesnet P, Bourre JM, Guerre-Millo M, et al. (1990) Tissue phospholipid fatty acid composition in genetically lean $(\mathrm{Fa} /-)$ or obese (fa/fa) Zucker female rats on the same diet. Lipids 25, 517-522.

68. Ma DW, Seo J, Switzer KC, et al. (2004) and membrane microdomains: a new frontier in bioactive lipid research. J Nutr Biochem 15, 700-706.

69. Buatois V, Baillet M, Becart S, et al. (2003) MHC class II-peptide complexes in dendritic cell lipid microdomains initiate the CD4 Th1 phenotype. J Immunol 171, 5812-5819.

70. Zilber MT, Setterblad N, Vasselon T, et al. (2005) MHC class II/CD38/CD9: a lipid-raft-dependent signaling complex in human monocytes. Blood 106, 3074-3081.

71. Huby RD, Dearman RJ \& Kimber I (1999) Intracellular phosphotyrosine induction by major histocompatibility complex class II requires co-aggregation with membrane rafts. $J$ Biol Chem 274, 22591-22596.

72. Anderson HA, Hiltbold EM \& Roche PA (2000) Concentration of MHC class II molecules in lipid rafts facilitates antigen presentation. Nat Immunol 1, 156-162.

73. Sanderson P, MacPherson GG, Jenkins CH, et al. (1997) Dietary fish oil diminishes the antigen presentation activity of rat dendritic cells. J Leukoc Biol 62, 771-777. 